\section{Rural district hospitals: Ambulance services, staff attitudes, and other impediments to healthcare delivery}

To the Editor: I was pleased to note the recent article and correspondence in the SAMJ dealing with the revival of rural district hospitals. ${ }^{[1,2]}$ However, many problems have to be overcome before this essential 'hub' of rural medical services will be restored. Two such problem areas were recently highlighted in our local and regional newspapers. I live in the rural Eastern Cape (EC), so my comments pertain only to this area.

According to an article in Die Burger, Oos-Kaap (2 October 2015), there is a huge shortage of facilities, especially casualty facilities, in EC rural areas. Casualty facilities will obviously not spring up miraculously, without properly functioning rural district hospitals to house and administer them. The article summarised a March 2015 report by the South African Human Rights Commission, after extensive research into the extremely poor health service delivery to patients in EC rural areas, and highlighted the insufficient ambulance services in the area: 12 ambulances to serve one million people v. the accepted norm of one ambulance per 10000 people. It also stressed the poor road conditions that make some remote areas inaccessible even if an ambulance is available when and where required. This reported lack of effective, reliable transport of patients is a major impediment to rural health care delivery, even should the district hospitals be re-engineered to full function.

The meagre services that are available at some of these existing rural district hospitals are sometimes crippled further by negative staff attitudes. A recent series published in a local newspaper (Advertiser, 28 August and 18 September 2015) reported unfortunate and unpleasant experiences at our local district hospital. The author expressed disappointment and shock about the (non-)treatment her father received at the casualty ward when he attended with an acute medical emergency: 'If you have a medical aid, you must go to a private hospital [the nearest private hospital is $350 \mathrm{~km}$ away], this hospital is only for indigent patients.' According to the same writer, a private patient was told 'You are not sick enough, you cannot see the doctor'; the patient was sent away without being assessed, only to have to return later.

Other first-hand reports of thinly disguised political posturing and racially loaded statements abound. I hesitate to comment on the apparently dysfunctional obstetric services, the unacceptable perinatal mortality rate, etc. (all of which is public knowledge locally) at this same rural district facility, which has very reasonable infrastructure, but is in dire and urgent need of revival and re-organisation. I suspect that it is but one of many such examples in the EC.

It is obvious that interdepartmental intervention is urgently required. Many things are needed when restoring a rural district hospital to be the essential nucleus of healthcare delivery in remote areas, as has been clearly outlined..$^{[1,2]}$

The purpose of this letter is to stress once more the importance of a reliable ambulance service to and from these hospitals, along roads that are usable. The rural hospital cannot play its role as 'hub' without a connecting transport lifeline. The attitudes of some staff members at some district hospitals have to be addressed. Proper training (and re-training) in the basic tenets of the ethos of healthcare are a top priority. Can South Africa ever hope to deliver acceptable healthcare to all its inhabitants, even in the remotest rural areas? I am of the opinion that it is possible. It will, however, require a concerted effort, and on the part of many also a change of heart. A positive and helpful attitude at all times is of the utmost importance when serving patients. It is always reassuring to have confidence and pride in one's local village hospital, however small it may be. We all need to work towards that goal.

\section{J du T Zaaijman}

Inxuba Yethemba, Eastern Cape, South Africa

zaaij@adsactive.com

1. Le Roux KWDP, Couper I. Rural district hospitals - essentials cogs in the district health system and primary healthcare re-engineering. S Afr Med J 2015;105(6):440-441. [http://dx.doi.org/10.7196/ SAMJ.9284

2. Bac M, Hugo J. Rural district hospitals - essential cogs in the district health system - and primary healthcare re-engineering. S Afr Med J 2015;105(9):702. [http://dx.doi.org/10.7196/SAMJnew.8379]

S Afr Med J 2015;105(12):1001. DOI:10.7196/SAMJ.2015.v105i12.10174 